\title{
Shelter construction for fish at the confluence of a river to avoid the effects of total dissolved gas supersaturation
}

Xia Shen ${ }^{a}$, Ran Li ${ }^{a}{ }^{a *}$, Juping Huang ${ }^{a}$, Jingjie Feng ${ }^{a}$, Weilin Xu', Ben R. Hodges ${ }^{\mathrm{b}}$ 


\section{ABSTRACT}

2 Total dissolved gas (TDG) supersaturation downstream has a negative environmental effect on fishes. It is caused by discharge from high dams and increases the incidence of gas bubble disease and fish mortality. Downstream of a high dam, there is an area with low TDG

5 saturation due to the gradual mass exchange of gases between the separation zone and the 6 mainstream and the long retention time in the confluence, which contributes to the dissipation 7 of saturated TDG at the confluence of the mainstream and its tributaries. This area can provide a temporary shelter for fish to avoid the effects of TDG supersaturation during dam discharge. A depth-averaged, two-dimensional model of TDG dissipation at a river confluence was established. The concentration field was verified by a flume experiment. A numerical simulation of the TDG at the confluence of the Zumuzu River and its tributary, the Mozigou River, was conducted. The simulation showed that the convergence of the tributary, which had a low TDG saturation level, could reduce the TDG saturation level of the mainstream. However, the low-saturation area was not large enough for fish to avoid the negative effects of TDG saturation due to a sharp river slope and a large flow ratio between the mainstream and its tributary. To expand the suitable shelter area with low TDG supersaturation levels in order to provide a suitable shelter for fish, some engineering measures were explored, including the excavation of the riverbed and the construction of resistance obstacles. After the engineering measures were introduced, we observed a 30-fold increase in the size of the area with low TDG saturation, which was as high as $10005 \mathrm{~m}^{2}$ at $110 \%$ of the TDG saturation. Combined with the comprehensive analyses of the flow velocity and the water depth, the 
confluence region was thought to be suitable to protect the fish from the effects of TDG supersaturation. This study provides an important reference for protecting fish during high dam discharge.

\section{Keywords:}

Confluence; total dissolved gas; supersaturation; shelter; fish protection

\section{Introduction}

Total dissolved gas (TDG) supersaturation is known to increase the incidence of gas bubble disease and fish mortality (Weitkamp and Katz, 1980; Weitkamp et al., 2003; Tan, 2006). Persistent TDG supersaturation has been observed in river reaches up to $500 \mathrm{~km}$ downstream during discharges from a high dam (Chen et al., 2009). Such discharges are typically periodic and operationally unavoidable, so developing methods for enhancing fish survival during TDG supersaturation events is critical to maintaining a balanced ecosystem. There are two likely approaches for improving fish survival: (i) developing methods to increase the dissipation rate of TDG supersaturation, and (ii) providing or enhancing refuge areas with lower TDG saturation. The latter idea is the focus of the present study. Previous studies have shown fish have some ability to detect and avoid areas of high TDG supersaturation (Chen et al., 2012; Wang et al., 2015), which makes establishment or enhancement of refuges a promising approach.

The mixing behavior at the confluence of two rivers is a well-studied phenomenon (Best and Reid, 1984) that has typically been focused on sediment, scour, turbulent mixing, and 
pollutant dilution. A key feature of a confluence is a region, sometimes extending far downstream, where the tributary water retains its identity and is not fully mixed across the main stem river. From the perspective of providing a refuge, we are interested in quantifying the area where the tributary water intrudes into the mainstream.

However, prior research on confluences is mainly concentrated on issues of sediment and mixing, whereas there are few studies of TDG. Therefore, research into hydrodynamics, transport and dissipation of TDG at confluences is needed to improve predictions of downstream areas with supersaturated TDG. Furthermore, this research provides a scientific basis for using a low TDG saturation region to improve the river ecosystem and provide mitigation measures for TDG supersaturation.

Confluences are inherently three-dimensional (3D) and contain non-hydrostatic eddy features (Bradbrook et al., 1998; Weber et al., 2001; Constantinescu et al., 2011), as shown in Fig.1. However, they have been adequately modeled for engineering purposes with the 2D shallow-water equations(Zhao et al., 2005). It can be expected that the complex 3D mixing processes at a confluence will enhance dissipation of TDG supersaturation (i.e. by increasing the rate at which supersaturated water encounters the free surface), but the subject has not been studied in either the laboratory or the field. As a starting point, herein the TDG supersaturation is treated as a transported passive scalar that is dissipated (i.e. transformed into air bubbles or released across the free surface) at a known rate based on prior field observations for the main stem river. The neglect of additional TDG dissipation at the confluence is conservative in that it causes an underprediction in the expected refuge area of lower TDG. 


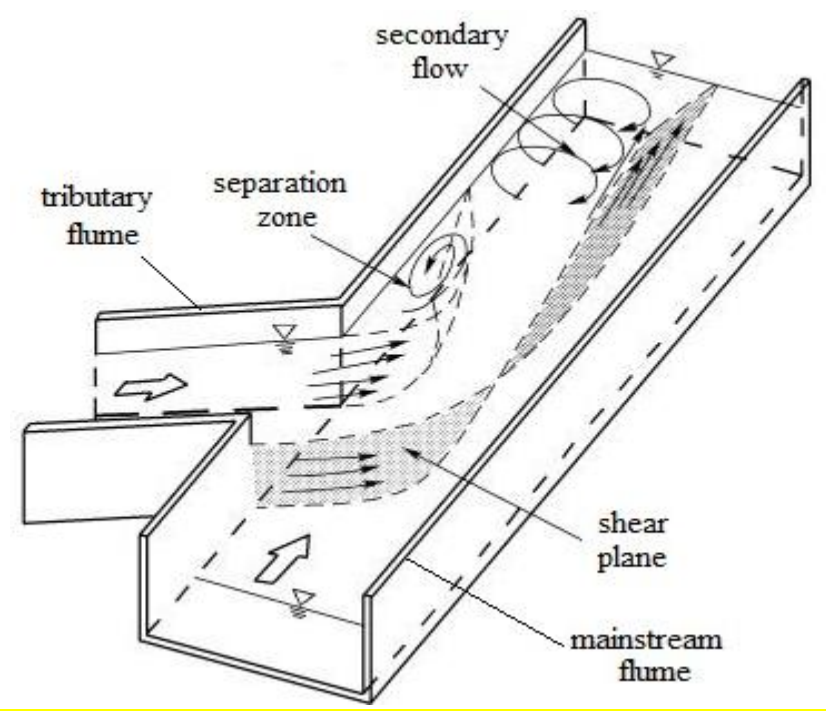

Fig. 1. The sketch of the unique flow characteristics at the confluence flume. (Biron and Lane, 2008)

Taylor (1944) was the first to develop an analytical model for a river confluence. This model predicted the tributary channel depth upstream of the junction. Best and Reid (1984) performed an experimental investigation on the characteristics of the separation zone with varying junction angles and flow ratios. They defined the separation zone shape index as the ratio of the width to the horizontal length of the separation zone, with a typical value of 0.19 . Using a numerical simulation Wang (2015) found that the shape of the separation zone at the confluence of the Yangtze River and the Jialing River was significantly affected by the topography. Thevethan et al. (2015) recently reported a field study for the confluence of the Negro and Solimoes Rivers including a series of velocity profiles, water quality, and seismic measurements to evaluate hydrodynamic and morphodynamic features of this confluence. Kang (2011) examined mixing at an idealized confluence, and is used herein as a validation case for our model.

There have been few studies of the TDG distribution and the gas-liquid interfacial mass transfer process near a river confluence. Observations of the Columbia River (United States 
Waterways Experiment Station, 1996, 1997) indicate, the mixing process between TDG supersaturated water from discharge with tail water in which the TDG is not supersaturated happened when the powerhouse is closed to dam. Most of the investigations on the dissipation process of supersaturated TDG focus on the natural rivers downstream of dams. The United States Army Corps of Engineers concluded that the TDG dissipation process can be modeled using first-order kinetic theory with field observations and theoretical analysis (United States Army Corps. of Engineers, 2005). The dissipation rate of TDG is modeled with dissipation coefficient, as a function of velocity, water depth and molecular diffusivity. Perkin (2004) and Johnson $(2007,2010)$ employed a depth-averaged, two-dimensional mathematical model to simulate the distribution of TDG within a few kilometers downstream of the Bonneville Dam and Ice Harbor Dam. Their dissipation coefficients were associated with wind speed. The dissipation coefficient has also been estimated from several experiments and field observations. Feng et al. (2010) developed a formula for a comprehensive dissipation coefficient from field observations of several rivers to replace the molecular diffusion coefficient proposed by Pickett et al. (2010). Although it has been convenient to use reaeration and dissolved oxygen studies as proxies for TDG in determining dissipation coefficients, the laboratory studies of Li et al. (2013) showed that TDG dissipation process is quantitatively different from reaeration, and the DO is not a good poxy for TDG. In field and laboratory studies, Feng (2014) showed that dissipation rate of TDG increase with higher turbulence and a longer retention time.

Laboratory research has demonstrated that some fish have the ability to detect and avoid avoid supersaturated TDG. Although it has not been directly observed in the field, it seems 
likely that fish could seek shelter in an area with low TDG supersaturation levels at a confluence to avoid the effects of the supersaturated TDG during a limited dam spill period. The present work examines the distribution of supersaturated TDG near a confluence in a numerical simulation. Potential intervention measures for enlarging the shelter area of low TDG were studied the model.

\section{Mathematical model}

\subsection{Numerical Model}

A depth-averaged, 2D model applying the Reynolds-Averaged, hydrostatic (shallow-water) Navier-Stokes equations was used to simulate a river confluence and the transport of TDG:

$$
\frac{\partial \zeta}{\partial t}+\frac{\partial(h+\zeta) u}{\partial x}+\frac{\partial(h+\zeta) v}{\partial y}=0
$$

$$
\frac{\partial u}{\partial t}+u \frac{\partial u}{\partial x}+v \frac{\partial u}{\partial y}=-g \frac{\partial \zeta}{\partial x}+v_{t}\left(\frac{\partial^{2} u}{\partial x^{2}}+\frac{\partial^{2} u}{\partial y^{2}}\right)+\frac{1}{\rho(h+\zeta)}\left(\tau_{s x}-\tau_{b x}\right)
$$

$$
\frac{\partial v}{\partial t}+u \frac{\partial v}{\partial x}+v \frac{\partial v}{\partial y}=-g \frac{\partial \zeta}{\partial y}+v_{t}\left(\frac{\partial^{2} v}{\partial x^{2}}+\frac{\partial^{2} v}{\partial y^{2}}\right)+\frac{1}{\rho(h+\zeta)}\left(\tau_{s y}-\tau_{b y}\right)
$$

$$
\frac{\partial h G}{\partial t}+u \frac{\partial h G}{\partial x}+v \frac{\partial h G}{\partial y}=\frac{\partial}{\partial x}\left(v_{t} \frac{\partial h G}{\partial x}\right)+\frac{\partial}{\partial y}\left(v_{t} \frac{\partial h G}{\partial y}\right)+h S_{C}
$$

$$
\text { where } u \text { and } v \text { are the depth-averaged flow velocity components in the } x \text { and } y \text { direction, }
$$

respectively, $t$ is the time, $h$ is the mean water depth, $\zeta$ is the difference between the surface elevation and the mean depth, $g$ is acceleration of gravity, $\rho$ is the water density, $v_{t}$ is an eddy viscosity coefficient, $\left(\tau_{\mathrm{sx}}, \tau_{\mathrm{sy}}\right)$ and $\left(\tau_{\mathrm{bx}}, \tau_{\mathrm{by}}\right)$ are the $x$ and $y$ direction of surface wind stress and the river bottom friction, G is the concentration of TDG, and $S_{C}$ is the sink dissipation of TDG, which is represented as $S_{C}=-k_{\mathrm{TDG}} G$, where $k_{\mathrm{TDG}} \mathrm{s}$ is the dissipation coefficient of the supersaturated TDG. 


\subsection{Model verification}

Our approach to the hydrodynamic simulation of a confluence follows similar works and applies a numerical model for hydrodynamics that was validated in Wang et al. (2014). To validate the scalar transport model, we developed a simulation of a laboratory experiment by Kang (2011) that used very small salt concentrations as a conservative tracer to identify tributary water.

Figure 2 shows the model representation of the Kang (2011) experiment with a mainstream flume of $23 \mathrm{~m}$ length and $1.0 \mathrm{~m}$ width, a tributary flume of $4 \mathrm{~m}$ length and $0.5 \mathrm{~m}$ width, and a junction angel of $60^{\circ}$ measured from the mainstream to the tributary. The flow rates of the mainstream flume and the tributary flume were $0.0511 \mathrm{~m}^{3} / \mathrm{s}$ and $0.04 \mathrm{~m}^{3} / \mathrm{s}$, respectively. The salinity of the mainstream flume and the tributary flume were 0 and 110 $\mathrm{mg} / \mathrm{l}$, respectively. Note that at this salinity level and these flow rates the density effects of the salt can be ignored. The model grid used 19577 grid cells in an unstructured triangular mesh, as shown in Fig. 2.

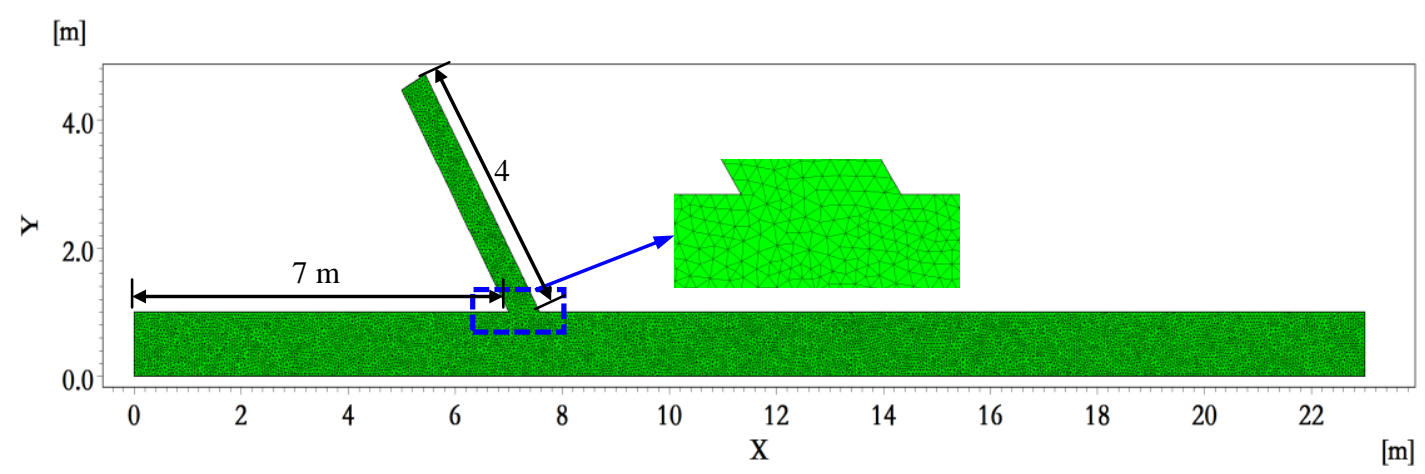

Fig. 2. Model grids in the validation domain for the numerical simulation of the Kang (2011) flume experiments.

Fig. 3 shows the salinity distribution at the confluence in the simulation. There is a 
141

separation zone at left bank near the branch flume downstream of the confluence. The velocity of the separation zone varies from $0.003 \mathrm{~m} / \mathrm{s}$ to $0.005 \mathrm{~m} / \mathrm{s}$, while the max velocity of the cross section is $0.03 \mathrm{~m} / \mathrm{s}$. The high density areas of salinity were mainly concentrated in the position near the left bank in the downstream. The shear plane and separation zone can be seen in Fig. 3. The salinity of the separation zone varies from $60 \mathrm{mg} / \mathrm{l}$ to $90 \mathrm{mg} / \mathrm{l}$. Model and experimental results are compared in Fig. 4. The error values at the measurement points between model and experiment range from $2.9 \%$ to $9.8 \%$, which is reasonable agreement.

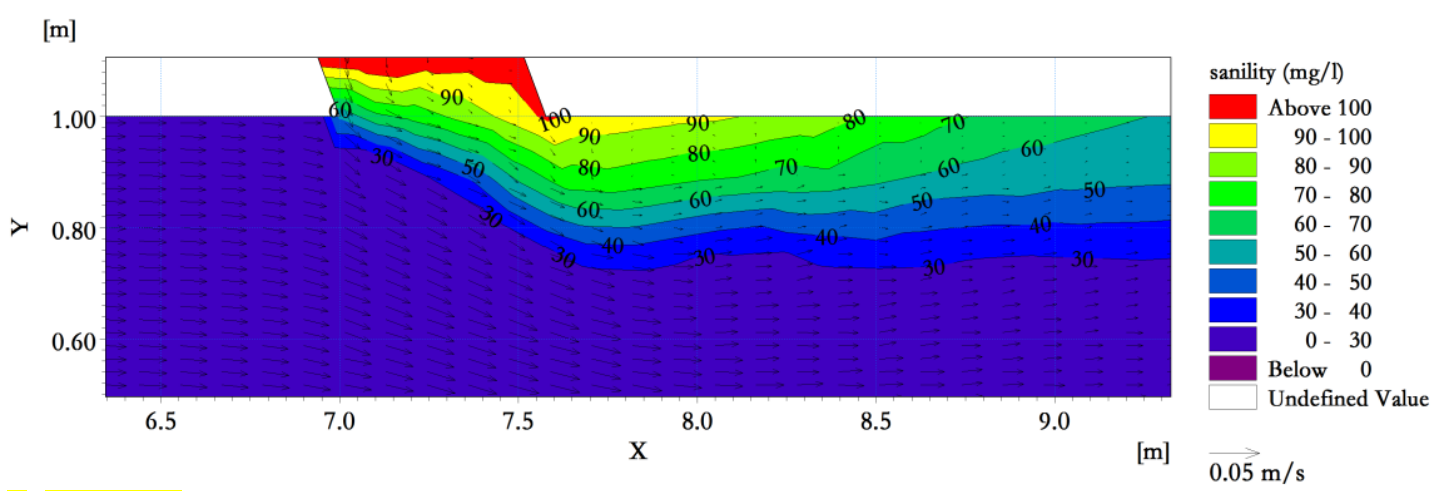

Fig. 3. Modeled salinity distribution at the confluence of the flume experiment

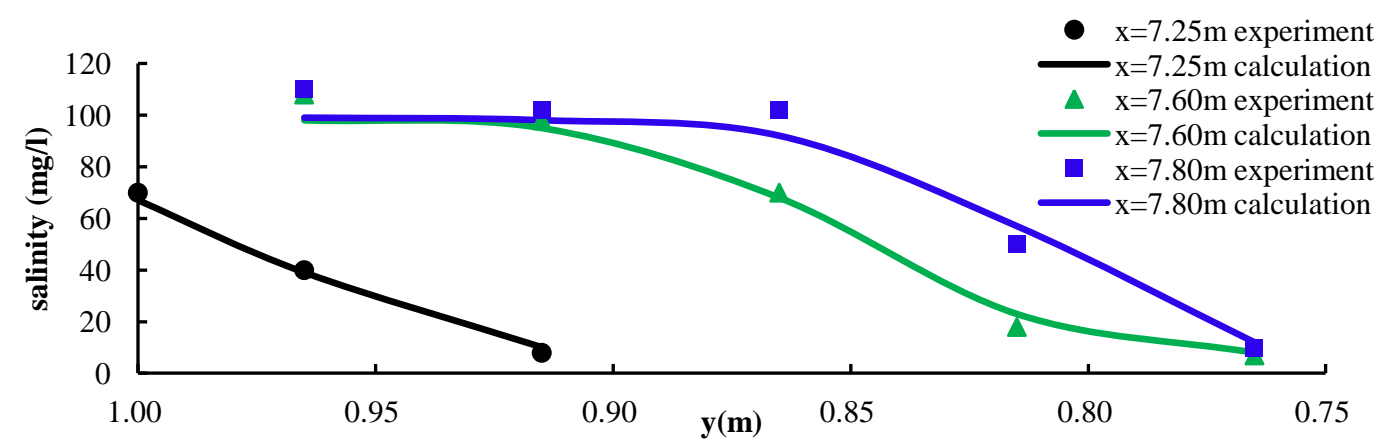

Fig. 4. Comparison of the salinity between the model and the experiment

\section{Study site}

As a study site we use a reach of the Zumuzu River (China) downstream of the Bala Dam 
where it is joined by the smaller Mozigou River.

\subsection{General conditions and boundary conditions}

The Zumuzu River is itself a tributary of the larger Daduhe River in Sichuan province, China. The dam height is $138 \mathrm{~m}$, with the normal water level of the Bala reservoir is $2920 \mathrm{~m}$ above mean sea level The normal storage capacity is $1.277 \times 10^{8} \mathrm{~m}^{3}$. The flood discharge structures include one spillway tunnel and one emptying tunnel. For a 2-year flood discharge, the supersaturated TDG level predicted by Li et al. (2009) is $130.5 \%$. This level of supersaturated TDG is thought to be harmful to the fish in the river. Therefore, mitigation measures to protect the fish are desirable.

The Mozigou River is a small tributary entering the Zumuzu River 500 m downstream of Bala Dam. The peak of the 2-year flood in the tributary is approximately $8.25 \mathrm{~m}^{3} / \mathrm{s}$, with TDG saturation of approximately $100 \%$. Because of the disparities in the flow rates, full mixing of the Mozigou River flow with the flood discharge in the Zumuzu can only reduce the $130.5 \%$ predicted TDG supersaturation down to $120 \%$, which is still hazardous to fish.

Field measurements for velocity, mixing, and TDG at the study site confluence are not available, so our work focuses on comparing a baseline numerical simulation of the known river morphology with simulations of proposed physical alterations to examine how these change the distribution area of different TDG levels.

\subsection{Domain and mesh division}

The computational domain, shown in Fig.5, in the Zumuzu river extends approximately $500 \mathrm{~m}$ upstream and 700m downstream of the confluence. For the Mozigou River, $300 \mathrm{~m}$ 
upstream of the confluence is included. The unstructured grid uses 29658 approximately uniform triangular elements with an average area of $50 \mathrm{~m}^{2}$ in each element. The flow rate of Zumuzu River and Mozigou River inlet are $635 \mathrm{~m}^{3} / \mathrm{s}$ and $8.25 \mathrm{~m}^{3} / \mathrm{s}$ respectively. The TDG saturation of Zumuzu River and Mozigou River inlet are 130\% and 100\% respectively.

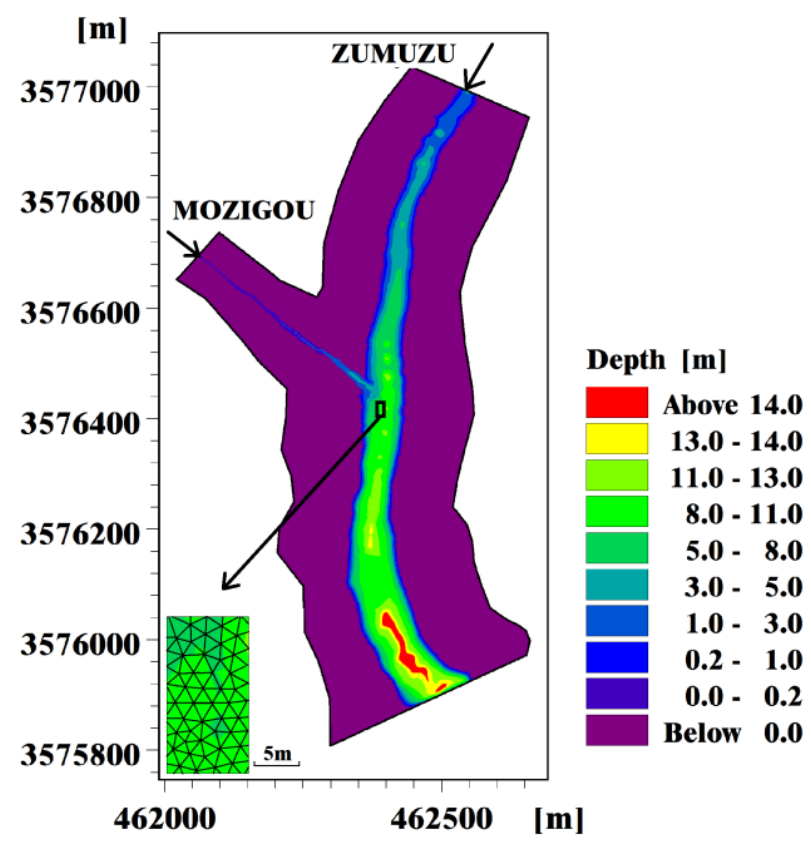

Fig. 5. Depth in the computational domain and local grids near the confluence

\subsection{Parameter determination}

The Smagorinsky coefficient used for the turbulence model was 0.28 , the Prandtl constant value was 1 , and the Manning coefficient for bottom roughness was set at 0.03 . These values are the same as those used in the validation experiment (Section 2.2). The dissipation coefficient of the supersaturated TDG was set at $2.78 \times 10^{-5} \mathrm{~s}^{-1}$, which matches field observation results in the Lancang River.

\subsection{Prediction results}



respectively. The range area of less than $0.5 \mathrm{~m} / \mathrm{s}, 1 \mathrm{~m} / \mathrm{s}$ and $2 \mathrm{~m} / \mathrm{s}$ of the velocity in the separation zone was $5 \mathrm{~m}^{2}, 660 \mathrm{~m}^{2}$ and $1202 \mathrm{~m}^{2}$, respectively. Due to the part or all of the life Ingram et al., 2011). Therefore, the velocity at the confluence was too large to provide a suitable environment for the fish to swim. Furthermore, the depth at the confluence was too small to protect the fish from the damaging effect of the supersaturated TDG. $\mathrm{m}^{2}$, respectively. 

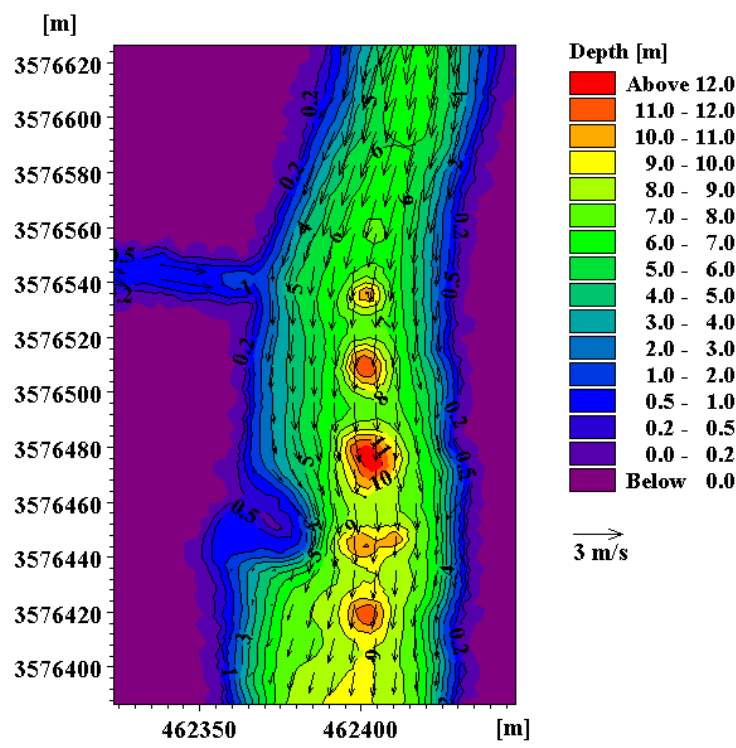

(a) Water depth and flow field

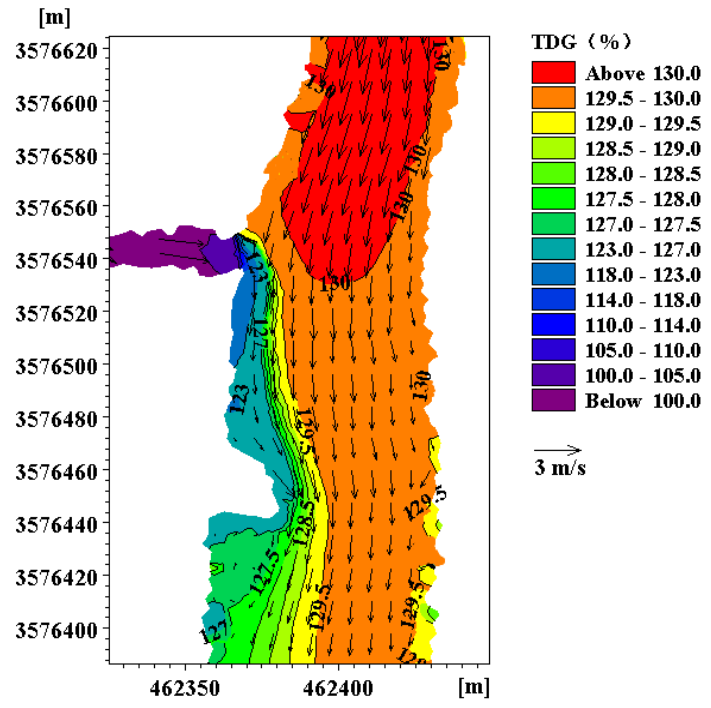

(b) TDG distribution

Fig. 6. Flow field and TDG distribution at the confluence.

\section{Shelter creation for fish}

According to the above-described simulation results, the low-saturation region was not large enough for the fish to avoid the negative effects due to a sharp river slope and the large flow ratio between the mainstream and the tributary. Previous research has shown that resistance obstacles, vegetation and other media in the TDG-supersaturated water can increase the solid-liquid interfacial area, decrease the water turbulence intensity and extend the resistance time in water. Consequently the dissipation of the supersaturated TDG is accelerated. To expand the area with low levels of supersaturated TDG and provide a suitable shelter for fish at the Mozigou confluences, some engineering measures were explored in the model, including the excavation of the riverbed and the use of resistance obstacles.

A possible approach to increasing the fish refuge area is to provide a longitudinal dam that directs the main-stem flow around the confluence and allow the tributary water to extend 
further into the main channel. One potential approach is shown in Fig. 7, which uses
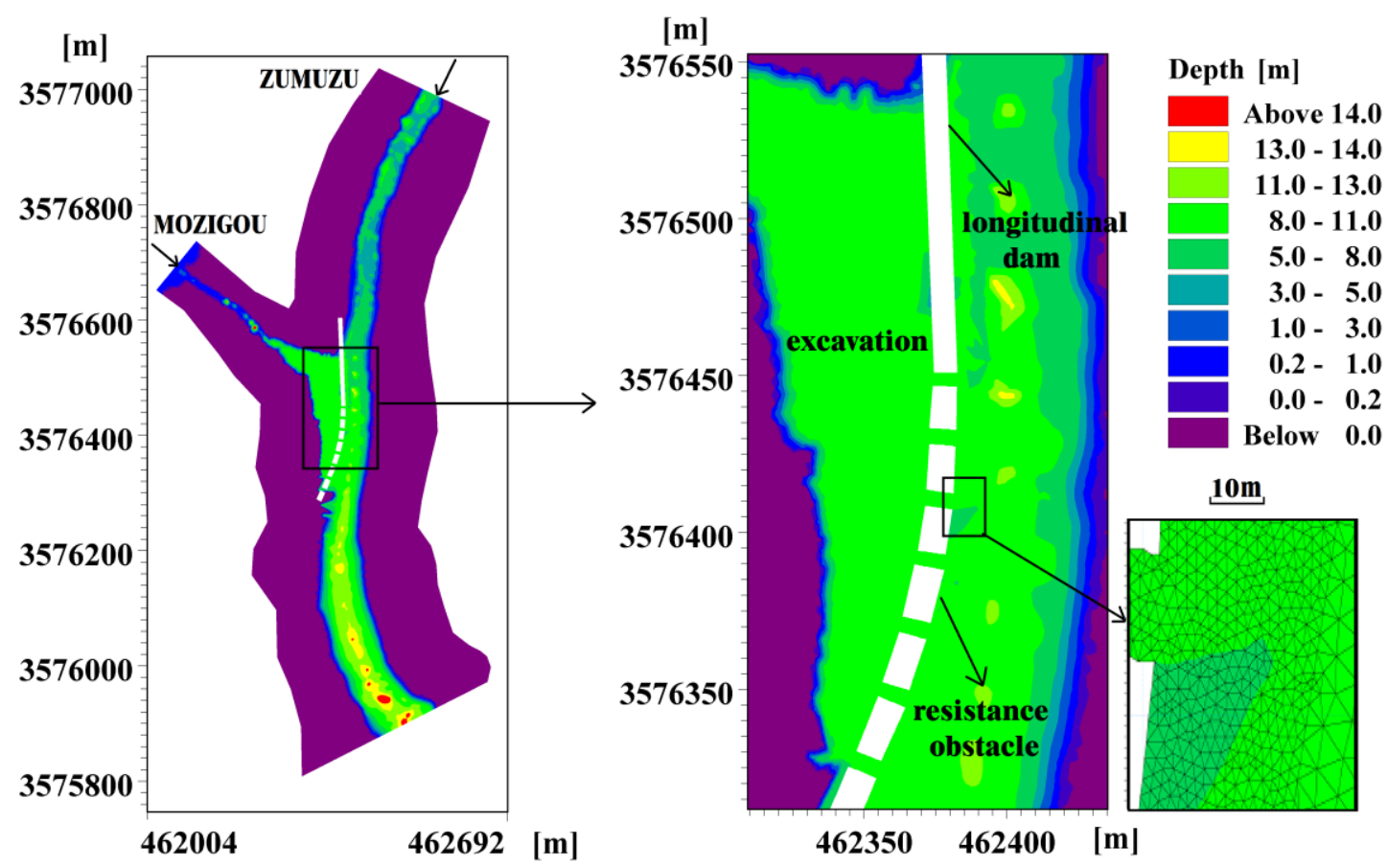

Fig. 7. A possible dam and resistance obstacles that have been simulated.

As shown in Fig. 8(a), engineering measures can increase the water depth and reduce the velocity at the confluence, which provides a better shelter area for fish survival and reproduction. The detailed results are shown in Table.1.

Fig. 8(b) shows that the area of low-saturation was enlarged after the engineering measures, which could protect the fish from the damaging effects of supersaturated TDG. The measures promoted tributary flow into the mainstream, reducing the backwater effect of the mainstream into the tributary while increasing the backwater effect of the tributary into the 
saturation. The resistance obstacles hindered the flow of the mainstream into the tributary, which allowed the low-saturation region to remain in a certain range. We observed that the 239 size of the saturation regions of below $110 \%, 115 \%$ and $120 \%$ were increased to $10005 \mathrm{~m}^{2}$, $24010470 \mathrm{~m}^{2}$ and $1116 \mathrm{~m}^{2}$, respectively, which was an approximately 180-fold, 47-fold and 241 30-fold difference from before the engineering measures. Based on research characterizing

242 fish tolerance (Huang et al., 2010; Chen et al., 2012; Wang et al., 2015), the simulation results

243 after the engineering measures were expected to meet the space requirements necessary for

244 fish to avoid the damaging effects of the supersaturated TDG.

\section{Table 1}

246 Area statistics of the different TDG level before and after the engineering measures.

\begin{tabular}{|c|c|c|c|c|c|c|c|c|c|c|}
\hline \multirow{3}{*}{ Case } & \multicolumn{10}{|c|}{ Area at the separation zone $\left(\mathrm{m}^{2}\right)$} \\
\hline & \multicolumn{4}{|c|}{ Depth (m) } & \multicolumn{3}{|c|}{ Velocity $(\mathrm{m} / \mathrm{s})$} & \multicolumn{3}{|c|}{ TDG $(\%)$} \\
\hline & $<3$ & $<4$ & $<5$ & $<8$ & $<0.1$ & $<1.0$ & $<2.0$ & $<110$ & $<115$ & $<120$ \\
\hline $\begin{array}{l}\text { Before } \\
\text { measures }\end{array}$ & 960 & 1280 & 1800 & 1800 & 0 & 660 & 1200 & 55 & 223 & 355 \\
\hline $\begin{array}{l}\text { After } \\
\text { measures }\end{array}$ & 0 & 0 & 0 & 11200 & 15200 & 15500 & 15500 & 10005 & 10470 & 11160 \\
\hline
\end{tabular}




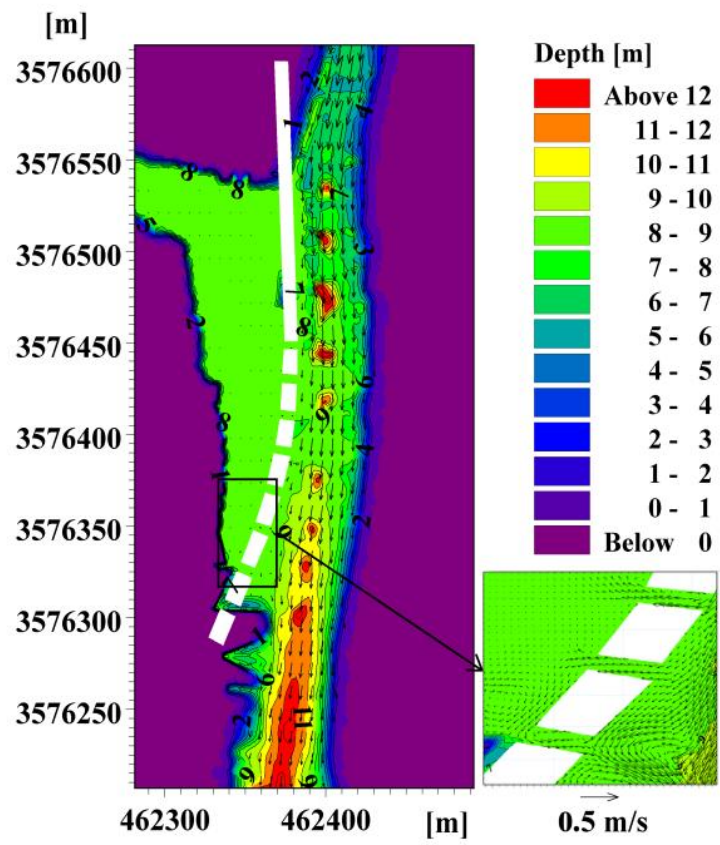

(a) Flow field

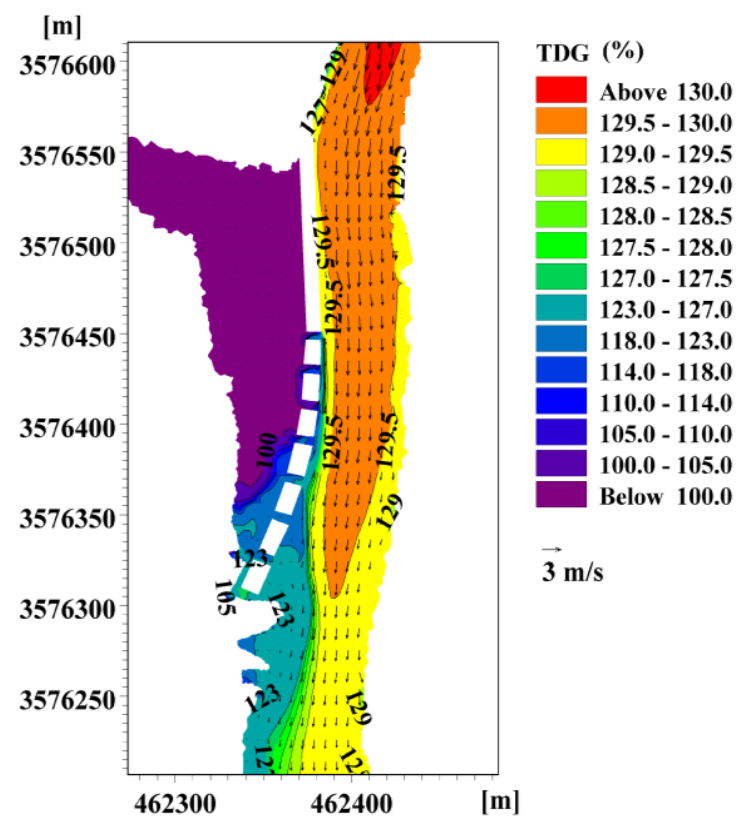

(b) TDG distribution

Fig. 8. Flow field and TDG distribution simulated with proposed alterations..

\section{Conclusions}

A depth-averaged, two-dimensional TDG model was established in this paper. The simulation of TDG at the confluence of the Zumuzu River and its tributary, the Mozigou River, were conducted. In addition, to expand the area with low TDG supersaturation levels and to provide a suitable shelter for fish, some potential engineering measures were explored. saturation of the mainstream. After the potential engineering measures were included in the model, deepening the riverbed and the installing resistance obstacles, the area of the low-saturation region was enlarged. This area could provide refuge space for fish to escape 
the utilization of a low TDG saturation region at a confluence to improve the river ecosystem and provide some mitigation measures reducing TDG supersaturation.

The numerical simulation study shows that potential engineering measures at a confluence could be beneficial to the ecological function of a river. The fundamental idea is that installing engineered measures to control the secondary flow mixing and distribution of low TDG water downstream of the confluence can create a low TDG refuge that otherwise might not occur because of high water velocities or insufficient depth of the natural confluence.. To optimize such installations in the future, we need to further improve our understanding of how 3D turbulence at a confluence enhances supersaturated TDG dissipation, and the effect of engineered structures on the dissipation rate. Understanding how the distribution of supersaturated TDG can be controlled is vital to protecting fishes from damage by supersaturated TDG. Due to the complexity of natural river conditions, the practical application of engineering measures need to be further studied in combination with engineering design and an assessment of fish survival.

Note that although many river systems have dams on connecting branches, it is unlikely that two high dams will be close enough that their supersaturation reaches will overlap. In the unlikely case of an overlap, the dam discharge operations should to be carefully considered in light of the present study. Of greater import is the potential for coupled operation between two dams on connecting branches: i.e. where a minor tributary has a dam further upstream that does not have a supersaturation impact at the confluence, it might be possible to increase the discharge during high TDG supersaturation conditions on the main stem river so as to increase the low TDG refuge area at the confluence. Because of the complex relationships between 
flow, turbulence, mixing and topography at a confluence, such systems will require careful study to understand the relationships between flow rates and refuge areas.

\section{Acknowledgments}

This work was supported by the National Natural Science Foundation of China (Grant No. 51279115, 51409182 and 2016YFC0401700). Co-author Hodges was partially supported by the U.S. National Science Foundation under Grant No. CCF-1331610.

\section{References}

Weitkamp, D.E., Katz, M., 1980. A review of dissolved gas supersaturation literature. Trans. Am. Fish. Soc, 109(6), 659-702.

Weitkamp, D.E., Sullivan, R.D., Swant, T., DosSantos, J., 2003. Gas bubble disease in resident fish of the lower Clark Fork River. Trans. Am. Fish. Soc, 132(5), 865-876.

Tan. D.C., 2006. Research on the lethal effect of the dissolved gas supper-saturation resulted from Three Gorges Project to Fish. Master thesis, Southwest University., Chongqing. (In Chinese).

Chen, Y.B., Peng, Q.D., Liao, W.G., 2009. Study on the evolution of dissolved gas in the middle reaches of the Yangze River after the operation of the Three Gorges Project. J. Hydro., 2(5), 1-5.

Chen, S.C., Liu, X.Q., Jiang, W., Li, K.F., Du, J., Shen, D.Z., Gong, Q., 2012. Effects of total dissolved gas supersaturated water on lethality and catalase activity of Chinese sucker (Myxocyprinus asiaticus Bleeker). J. Zhejiang Univ. Sci. B., 13(10), 791-796.

Wang, Y.M., Liang, R.F., Tuo, Y.C., Li, K.F., Hodges, B.R., 2015. Tolerance and avoidance behavior towards gas supersaturation in Rock Carp Procypris rabaudi with a History of Previous 
Exposure. N. Am. J. Aquacult, 77(4), 478-484.

Best, J.L., Reid, I., 1984. Separation zone at open-channel junctions. J. Hydraul. Eng, 110(11), $1588-1594$. Bradbrook, K.F., Biron, P. M., Lane, S. N., Richards, K.S. and Roy, A.G., 1998. Investigation of controls on secondary circulation in a simple confluence geometry using a three-dimensional numerical model. Hydrol. Process., 12(8), 1371-1396.

Weber, L.J., Schumate, E.D., Mawer, N., 2001. Experiments on flow at a 90 open-channel junction. J. Hydraul. Eng, 127(5), 340-350.

Constantinescu, G., Koken, M., Zeng, J., 2011. The structure of turbulent flow in an open channel bend of strong curvature with deformed bed: Insight provided by detached eddy simulation. Water. Resour. Res., 47.

Zhao, S.W., Mao, Z.Y., Luo, S., Wu, R., 2005. Depth-averaged turbulence models for flow simulation at equal-width open-channel junction. J. Hohai Univ., 33(5), 494-499. (In Chinese)

Biron P M., Lane S. N., 2008. Modelling hydraulics and sediment transport at river confluences. River confluences, tributaries and the fluvial network, 17-43.

Taylor, E. H., 1944. Flow characteristics at rectangular open-channel junctions. Trans. ASCE, 109:893-902.

Wang, X.K., Zhou, S.F., Ye, L., Wang, H.Z., 2015. Numerical simulation of confluence flow structure between Jialing River and Yangtze River. Adv. Water Sci. 26 (3), 372-377. (In Chinese)

Trevethan, M., A. Martinelli, M. Oliveira, M. Ianniruberto, and C. Gualtieri., 2015. Fluid dynamics, sediment transport and mixing about the confluence of Negro and Solimões rivers, Manaus, 
Brazil. In $36^{\text {th }}$ IAHR World Congress, The Hague, The Netherlands, June 28-July 3, 2015, Paper

80094.

Kang, P., 2011. Study on the Flow Field and Pollutants Diffusion at the Flow Confluence. Master thesis, Sichuan University., Chengdu. (In Chinese)

Waterways Experiment Station, 1996. Field data line plots R. Dallesport, WA: Waterways Experiment Station, Columbia Basin Limnological Research Facility.

Waterways Experiment Station, 1997. Field data line plots R. Dallesport, WA: Waterways Experiment Station, Columbia Basin Limnological Research Facility.

United States Army Corps. of Engineers, 2005. Technical Analysis of TDG Processes. US Army Corps of Engineers -Northwest Division, Environmental Resources and Fish Planning Offices.

Perkins, W.A., Richmond, M.C., 2004. Modular Aquatic Simulation System in Two Dimensions: Theory and Numerical Methods. PNNL-14820-1. Pacific Northwest National Laboratory, Richland, Washington.

Johnson, E.L., Clabough, T.S., Peery, C.A., Bennett, D.H., Bjornn, T.C., Caudill, C.C., Richmond, M.C., 2007. Estimating adult Chinook Salmon exposure to dissolved gas supersaturation downstream of hydroelectric dams using telemetry and hydrodynamic models. River. Res. Appl., 2007. 23(9), 963-978.

Johnson, E.L., Clabough, T.S., Caudill, C.C., Keefer, M. L., Peery, C.A., Richmond, M.C., 2010. Migration depths of adult steelhead Oncorhynchus mykiss in relation to dissolved gas supersaturation in a regulated river system. J. Fish. Biol., 76(6), 1520-1528.

Feng, J.J., Li R., Li, K.F., 2010. Study on release process of supersaturated total dissolved gas downstream of high dam. J. Hydraul. Eng. 29(1), 7-12. (In Chinese) 
349 Mid-Columbia River and Lake Roosevelt, submittal report. Washington, Washington State 350 Department of Ecology Publication. coefficient of supersaturated total dissolved gas. J. Cent. South Univ., 21, 1995-2003. replenishment in wetlands by reservoir operation. Ecol. Eng., 62, 71-76.

Nykänen, M., Huusko, A., 2002. Suitability criteria for spawning habitat of riverine European grayling, J. Fish Biol., 60(5): 1351-1354. 